УДК 621.373 .52

\title{
ДИНАМИКА ТЕМПЕРАТУРНО-ЧАСТОТНЫХ ПРОЦЕССОВ В МНОГОЧАСТОТНЫХ КВАРЦЕВЫХ ГЕНЕРАТОРАХ С ЦИФРОВОЙ КОМПЕНСАЦИЕЙ РЕЖИМНОЙ НЕСТАБИЛЬНОСТИ РЕЗОНАТОРА
}

\author{
ТАРАНЧУК А. А., ПИДЧЕНКО С. К., ХОПТИНСКИЙ Р. П.
}

Хмельниикий национальный университет, Украина, Хмельниикий, 29016, ул. Институтская, 11

\begin{abstract}
Аннотация. Рассмотрены особенности построения технически инвариантных к температурным воздействиям многочастотных кварцевых генераторов. Проведен анализ термодинамических характеристик многочастотных температурно-компенсированных кварцевых генераторов в условиях нестационарности теплового режима пьезорезонатора. Определена объемная плотность источника тепла при возбуждении кварцевого резонатора. Исследованы термодинамические процессы, происходящие в многочастотных кварцевых генераторах на этапе установления колебаний кварцевого резонатора. Доказана необходимость учета термодинамической составляющей при исследовании быстропротекающих тепловых процессов в кварцевых резонаторах. Дана оценка эффективности использования многочастотно-алгоритмического подхода к обеспечению инвариантности пьезорезонансных устройств. Показано, что использование даного подхода позволяет существенно снизить температурную нестабильность кварцевых генераторов и сократить время готовности данных устройств из-за более точной компенсации начальных выбегов частот
\end{abstract}

Ключевые слова: инвариантные пьезорезонансные устройства; многочастотный кварцевый генератор; кварцевый резонатор; динамика колебаний; температурно-частотные сдвиги; компенсация температурной нестабильности

\section{ВВЕДЕНИЕ}

Повышение температурной стабильности кварцевых генераторов (КГ) и устройств на их основе обычно связывают с конструктивно-технологическими методами, лидирующее место среди которых занимает термостатирование [1-3], и с классическими функционально-компенсационными методами, основывающимися на идентификации возмущающих воздействий с помощью отдельных датчиков, пространственно разнесенных с областью возбуждения колебаний пьезоэлемента (ПЭ) [4-6].

Однако эти методы вступают в противоречие с требованиями микроминиатюризации (элементы поверхностного SMD-монтажа), повторяемости характеристик, уменьшения энергопотребления, повышения надежности и улучшения эксплуатационных свойств. Например, использование резонаторов-термостатов не всегда оправданно как с позиций энергетических и массогабаритных показателей, так и в связи с большим временем выхода на режим термостабилизации (время готовности), необходимым для стабилизации тепловых процессов в кварцевых резонаторах (КР) [7].

Эффективным решением данной проблемы в пьезорезонансных (кварцевых) устройствах (ПРУ) является использование многочастотно-алгоритмического подхода к обеспечению инвариантности ПРУ, основанного на его 